\title{
AVALIAÇÃO DA EDUCAÇÃO SUPERIOR BRASILEIRA: RELEVÂNCIA, DIVERSIDADE, EQUIDADE E EFICÁCIA DO SISTEMA EM TEMPOS DE MERCANTILIZAÇÃO*
}

\author{
Júlio C. G. Bertolin*
}

Recebido em: 15 de setembro de 2008

Aprovado em: 06 de março de 2009

*Dr. em Educação pela Universidade Federal do Rio Grande do Sul (UFRGS), Prof. da Universidade de Passo Fundo (UPF), foi membro da Comissão Especial de Avaliação (CEA) do MEC, que elaborou a proposta original do Sinaes. E-mail: julio@upf.br

Resumo: Este artigo teve como objetivo avaliar e medir o desenvolvimento da qualidade do sistema de educação superior brasileiro no período 1993-2004. Considerou-se que o período escolhido está associado à intensificação das políticas de mercantilização da educação superior brasileira. A partir de um modelo conceitual de qualidade e de um sistema de indicadores desenvolveu-se a avaliação e medição da qualidade do sistema de educação superior brasileiro. O estudo indicou que, em tempos de mercantilização, a qualidade da educação superior brasileira não se desenvolveu positivamente, visto que no período estudado não foram encontradas evidências claras de melhorias em termos de relevância, eqüidade, diversidade e eficácia.

Palavras-chave: Educação superior. Avaliação de sistema. Mercantilização da educação superior. Avaliação da qualidade em educação superior. Sistema de indicadores de SES.

\section{EVALUATION OF BRAZILIAN HIGHER EDUCATION: RELEVANCE,DIVERSITY, EQUITY AND EFFICACY OF THE SYSTEM IN TIMES OF MERCANTILIZATION}

Abstract: The purpose of this article is to evaluate and measure the development of the quality of the Brazilian higher education system during the period of 1993 to 2004. The chosen period was considered to be associated with the intensification of the mercantilization of Brazilian higher education. The evaluation and measurement of the system's quality was developed based on a conceptual model of quality and a system of indicators. The study showed that, in times of mercantilization, the quality of Brazilian higher education did not develop positively, since in the period researched no clear evidence was found of improvements in terms of relevance, equity, diversity and efficacy.

Keywords: Higher education. Evaluation system. Mercantilization of higher education. Quality assessment in higher education. System-level indicators for higher education.

\section{Introdução}

A existência de instituições privadas e a cobrança de taxas dos alunos na educação superior não é um fenômeno recente, pois desde o surgimento da universidade na Europa medieval tais práticas são observadas. Nos últimos anos, porém, mudanças mais profundas e significativas sobre a natureza privada dos meios e dos fins da educação superior foram implementadas em quase todo o

\footnotetext{
*Obs: O presente trabalho foi realizado com apoio da Capes, Coordenação de Aperfeiçoamento de Pessoal
} de Nível Superior - Brasil. 
mundo. Uma "nova estrutura tem sido caracterizada por duas formas de privatização: o crescimento de instituições particulares e a crescente proporção de financiamento privado para as universidades públicas" (MCCOWAN, 2005, p. 1). Entretanto, as mudanças recentes que em alguns países começaram no final da década de 1980 vão além da simples ampliação das redes e do financiamento privados. O estabelecimento de mecanismos de mercado como forma de regulação, a emergência do managerialismo (modelos gerenciais empresariais) em instituições estatais e o estabelecimento efetivo de quase-mercados e mercados competitivos, também são fenômenos significativos da recente tendência de mercantilização da educação superior. Pode-se dizer que a mercantilização da educação superior é

o processo em que o desenvolvimento dos fins e dos meios da educação superior, tanto no âmbito estatal como no privado, sofre uma reorientação de acordo com os princípios e a lógica do mercado e sob a qual a educação superior, gradativa e progressivamente, perde o status de bem público e assume a condição de serviço comercial. (BERTOLIN, 2007a, p.107)

No Brasil, foi somente no ano de 1995 que políticas mercantilistas foram tomadas para o setor educacional. A partir de diretrizes estabelecidas na Reforma do Estado estabeleceu-se a Reforma do Ensino Superior, comandada pelo ministro da Educação, o economista Paulo Renato Souza, do governo de Fernando Henrique Cardoso. O pano de fundo econômico-financeiro que embasou as reformas da educação superior no Brasil na última da década foi o ajuste neoliberal da economia (LEITE, 2003). Assim, o governo instituiu uma reforma educacional que observou os ditames de instituições financeiras multilaterias. Uma das políticas mais conhecidas recomendada pelo Banco Mundial em 1994, o redirecionamento de recursos da educação superior para a educação fundamental, foi implementada no Brasil por meio do incentivo governamental para a expansão de instituição privadas e da publicação de uma nova legislação para a educação superior. Em 1989 os recursos destinados as Instituições Federais de Ensino Superior (Ifes) correspondiam a 0,97\% do PIB e, gradativamente, foram caindo até atingirem em 2001 apenas 0,61\% do PIB, ou seja, uma queda de 34\% no período (SGUISSARDI, 2005).

Em 15 de abril de 1997 foi publicado o decreto $\mathrm{n}^{\circ} 2.207^{1}$ que criou a figura

1 Pode-se dizer que juntamente com a LDB, lei no 9.394, de 20.12.1996, e a lei no 9.131, de 24.11.1995, que previu o Provão, o decreto ${ }^{\circ}$ 2.207, de 15.4.1997, fundamentou do ponto de vista legal a emergência da mercantilização da educação superior brasileira. $\mathrm{O}$ decreto $\mathrm{n}^{\circ} 2.207$ foi revogado pelo decreto $\mathrm{n}^{\circ} 2.306$, de 19.8.1997, que, por sua vez, foi substituído pelo decreto $\mathrm{n}^{\circ}$ 3.806, de 9.7.2001. Atualmente os decretos $\mathrm{n}^{\circ}$ 5.773 de 9.5.2006 e n ${ }^{0} 5.786$ de 24.5.2006 dispõem sobre o exercício das funções de regulação, supervisão e avaliação de instituições de educação superior e cursos superiores de graduação. 
dos centros universitários (instituições não universitárias com autonomia para criar cursos de graduação) e citou, pela primeira vez, as entidades mantenedoras com fins lucrativos que estão submetidas à legislação que rege as sociedades mercantis. Segundo dados do Instituto Nacional de Estudos e Pesquisas Educacionais “Anísio Teixeira” - Inep, em 1997 existiam 689 instituições privadas de educação superior; já, em 2003, passaram a ser 1652, ou seja, um crescimento da ordem de $140 \%$ em seis anos. Por outro lado, o número de instituições públicas decresceu no mesmo período, passando de 211 para 207. Entre os anos de 1998 e 2002 foram criadas, em média, 2,5 instituições por dia (INEP, 2006a). Entre 1994 e 2002, o número de alunos da rede pública passou de 690 mil para pouco mais de um milhão, ao passo que na rede privada o número de alunos passou de 970 mil para 2,4 milhões (INEP, 2004). Assim, a participação do setor privado nos cursos de graduação no Brasil, considerando o número de alunos matriculados, passou a ser uma das maiores do mundo.

Outra importante política desenvolvida no âmbito da educação superior brasileira foi a implantação de um processo de avaliação de concepção regulatória que gerava competição. A avaliação implantada adquiriu repercussão nos órgãos de imprensa que anualmente divulgavam uma classificação (ranking) dos cursos de graduação submetidos ao Provão. Tal divulgação gerou uma lógica de concorrência entre as diversas instituições de educação superior no sentido de conquistar maior destaque em relação aos "concorrentes" nos resultados dos exames. (DIAS SOBRINHO; RISTOFF, 2003)

Portanto, assim como em muitos países centrais e periféricos, na década de 1990 a educação superior brasileira entrou num claro processo de mercantilização de seus meios e fins. Para os que defendem a idéia de mercantilizar a educação superior, este nível de ensino deve ser definido como bem privado ou serviço comercial, prestando-se, assim, às regras de mercado. Nesse sentido, alguns autores argumentam que a educação superior não pode ser tratada como um bem público, visto que apresenta características de bem privado, tais como condições de rivalidade, de exclusividade e de recusa (JOHNSTONE, 1998). Dentre as principais justificativas para a ampliação da mercantilização está o argumento de que a competição de mercado induz à inovação e à adaptação dos sistemas às novas necessidades, o que dificilmente seria possível com a coordenação baseada no Estado ou na academia. Por outro lado, diversos e reconhecidos investigadores defendem o princípio da educação superior como bem público, apresentando, entre outros argumentos, que o mercantil, bem ao contrário das características da universidade, possui interesses de curto prazo (SANTOS, 2004). Entretanto, não obstante 
a existência de divergência de opiniões, o fato é que o contexto atual é de ampliação da lógica do mercado nos sistemas e instituições de educação superior em diversos e diferentes países.

Atualmente, portanto, além de estudar as origens e as características da mercantilização, também é importante investigar os impactos de tal fenômeno no desenvolvimento e na qualidade da educação superior. Será que, no campo da educação, e especialmente na educação superior, a competição do mercado provoca eficiência e eficácia, melhores resultados sociais e desenvolve a eqüidade? Os estudos desenvolvidos até o momento sobre as recentes mudanças de tendência mercantil na educação superior ainda não permitem conclusões definitivas sobre os impactos nos sistemas nacionais de educação.

O presente trabalho busca contribuir no aprofundamento do conhecimento acerca dos impactos da mercantilização sobre o desenvolvimento da qualidade sistema brasileiro de educação superior ${ }^{2}$ (Sesb). Por meio do desenvolvimento de abordagens teórico-conceituais sobre qualidade de educação, operacionalização da qualidade em forma de indicadores de qualidade, levantamento de dados e informações sobre o sistema de educação e de análises interpretativas do comportamento dos indicadores ao longo do período 1994-2003, esse artigo apresenta uma avaliação e medição da qualidade do sistema de educação superior brasileiro em tempos de mercantilização.

\section{Sistema de indicadores para avaliar a qualidade do SESB}

Alguns dos mais importantes organismos internacionais têm baseado avaliações, medições ou 'operacionalização' do desempenho dos sistemas nacionais de educação por meio de sistemas de indicadores, que consideram aspectos de entradas, processo e saídas. Dentre outros, destacam-se os sistemas de indicadores desenvolvidos pela Unesco, Comissão Européia e pela OCDE. Mais recentemente, um número crescente de países também tem organizado sistemas de indicadores e publicações de avaliação dos seus sistemas de educação, dentre os quais se incluem Bélgica, Canadá, Dinamarca, Espanha, EUA, Finlândia, França, Holanda, Luxemburgo e Reino Unido (NAVARRA, 2004). O entendimento conceitual do Laboratorio Latinoamericano de Evaluación de la calidad

2 Do ponto de vista legal, não existe um sistema nacional de educação superior brasileiro único. No presente trabalho, a sigla Sesb (SES brasileiro) será utilizada num sentido amplo para referir-se à existência de órgãos estatais de regulação e avaliação da educação superior e de IES postos a operar conjuntamente a partir dos marcos legais e das políticas em curso. 
de la educación de qualidade tem "estreita relação com o nível de logro dos objetivos educacionais, no marco dos programas oficiais de estudo, levando em conta as variáveis de insumo [ou entradas] e especialmente processo". O conceito subjacente do órgão determina que

o nível de qualidade da educação consiste basicamente na definição de um conjunto de variáveis que proporcione, em forma sistemática, um quadro confiável e válido acerca do estado dos sistemas de educação e que pode ser utilizado para colaborar na orientação e ações de melhoria (UNESCO, 1997, p. 7)

Os sistemas de indicadores procuram superar a obtenção de uma simples soma de dados ao agrupar indicadores simples ou compostos em função de fatores e aspectos que lhes dêem sentido e uma visão significativa do estado dos sistemas de educação (GARCIA, 2000). Portanto, pode-se dizer, com segurança, que os recentes modelos conceituais e operacionais elaborados com vistas a avaliar, medir e monitorar o desenvolvimento e a qualidade dos sistemas de educação têm se baseado em estruturas sistêmicas de indicadores que consideram aspectos de (i) entradas e/ou recursos, de (ii) processo e de (iii) resultados e/ou de saídas.

Dessa forma, não obstante a existência e possibilidade de outras formas de organização, os sistemas de indicadores proposto para avaliar e medir o desenvolvimento e a qualidade dos sistemas de educação superior (SES) geralmente possuem estruturas sistêmicas com elementos de entradas, processo e resultados.

No Brasil, o principal órgão responsável pelos estudos e estatísticas da educação superior é o Inep. Estudos recentes demonstraram que as informações disponibilizadas pelo Inep são insuficientes para a avaliação e acompanhamento da qualidade do sistema de educação superior brasileiro - Sesb (BERTOLIN, 2007a). Não obstante possuir relevantes dados, o Censo da Educação Superior, que se baseia em informações repassadas pelas instituições ao Inep, não permite uma medição e avaliação do Sesb de forma sistêmica completa. Diversas e importantes informações, como, por exemplo, taxas de empregabilidade dos egressos, nível de internacionalização do sistema, investimento e tempo de ensino relativo às $\mathrm{TIC}$, financiamento privado detalhado por organização acadêmica, entre outros, não são encontradas nas bases de dados do Inep para períodos recentes. Portanto, a avaliação do desenvolvimento e da qualidade do SES por meio de um sistema de indicadores ainda não é realizada no Brasil.

Dessa forma, com o objetivo de avaliar o desenvolvimento da qualidade do sistema de educação superior brasileiro em tempos de mercantilização, o 
presente trabalho se baseia no sistema de indicadores proposto para o Sesb por Julio C. G. Bertolin (2007b) (Figura 1). Tal sistema foi construído levando em considerações os seguintes aspectos: (i) o conceito de qualidade em educação superior (ES) como eficácia, diversidade, relevância e eqüidade; (ii) os modelos de indicadores sistêmicos estruturados em aspectos de entradas, processo e resultados; (iii) os indicadores e aspectos de avaliação de SES propostos pelos organismos internacionais Unesco-Cespes, OCDE e BM; (iv) os aspectos socioculturais e econômicos do Brasil contemporâneo para melhor avaliar a relevância do Sesb.

\section{Medição dos indicadores da qualidade do SESB no período 1994-2003}

A fim de investigar o desenvolvimento da qualidade da educação superior brasileira em tempos de mercantilização, o sistema de indicadores será utilizado como modelo referencial para se desenvolver a observação do comportamento dos aspectos da qualidade do Sesb no período 1994-2003. Como para o período a ser avaliado e medido não existem informações coletadas para todos os indicadores propostos, a observação do desenvolvimento da qualidade do Sesb em alguns aspectos será limitada aos dados e informações disponíveis. No caso dos indicadores de entradas sobre investimento no Sesb no período 1994-2003, por exemplo, a maior parte das informações disponíveis e confiáveis refere-se ao financiamento estatal do sistema global de educação. São escassas as informações sobre o financiamento privado e mesmo as informações públicas carecem de um maior detalhamento relativo às parcelas específicas aos subsistemas. Da mesma forma, existe limitação de disponibilidade de informações acerca de aspectos e indicadores de processo e resultados do Sesb no período estudado.

Entretanto, não obstante tais dificuldades, algumas medições, estimativas e, por conseguinte, acompanhamento das tendências de evolução de indicadores podem ser realizadas com vistas à avaliação do desenvolvimento da qualidade do Sesb no período 1994-2003. As fontes primárias principais de dados e estatísticas acerca da educação superior brasileira são o MEC e o IBGE. Através de publicações e de tabelas em planilhas eletrônicas, disponíveis nos sítios do MEC e de suas agências, tais como o Inep e a Capes, é possível ter acesso ao Censo da Educação Superior (que possui informações repassadas pelas instituições de ensino superior - IES - anualmente), aos resultados dos exames (Provão) aplicados aos concluintes dos cursos de graduação e aos dados relativos ao sistema de pós-graduação do país. O Inep, quando solicitado 


\begin{tabular}{|c|c|c|}
\hline \multirow{4}{*}{ Entradas } & $\begin{array}{l}\text { A-Investimento } \\
\text { em educação }\end{array}$ & $\begin{array}{l}\text { A1. Porcentagem de investimento estatal e privado em ES em relação } \\
\text { ao PIB } \\
\text { A2. Porcentagem de investimento estatal em ES em relação ao total } \\
\text { investido em educação } \\
\text { A3. Investimento com educação superior por discente: geral, estatal } \\
\text { e privado }\end{array}$ \\
\hline & $\begin{array}{l}\text { B-Investimento } \\
\text { em pesquisa }\end{array}$ & $\begin{array}{l}\text { B1. Investimento em P\&D na ES: geral, estatal e privado } \\
\text { B2. Investimento estatal em P\&D por tipo de instituição (estatal, privada, } \\
\text { universidades, não-universidade, tecnológica) }\end{array}$ \\
\hline & $\begin{array}{l}\text { C-Investimento } \\
\text { em TIC }\end{array}$ & C1. Investimento em TICs para a ES: geral, \\
\hline & $\begin{array}{l}\text { D-Quantidade e } \\
\text { formação docente }\end{array}$ & $\begin{array}{l}\text { D1. Razão entre discentes e docentes com alta titulação } \\
\text { D2. Razão entre discentes e todos os docentes } \\
\text { D3. Porcentagem de docentes com mais alta titulação obtida no exterior }\end{array}$ \\
\hline \multirow{7}{*}{ Processo } & $\begin{array}{l}\text { E-Número de } \\
\text { horas de ensino }\end{array}$ & $\begin{array}{l}\text { E1. Número da carga horária média dos cursos de graduação } \\
\text { E2. Porcentagem de tempo dos docentes dedicados a P\&D }\end{array}$ \\
\hline & $\begin{array}{l}\text { F-Acesso e utili- } \\
\text { zação das TIC } \\
\end{array}$ & $\begin{array}{l}\text { F1. Porcentagem de tempo de ensino em que os cursos de graduação } \\
\text { utilizam TIC }\end{array}$ \\
\hline & $\begin{array}{l}\text { G-Número de } \\
\text { horas, salário e }\end{array}$ & $\begin{array}{l}\text { G1. Taxa média de dedicação de tempo dos docentes para ES } \\
\text { G2. Média salarial dos docentes da ES: geral, estatal e privada }\end{array}$ \\
\hline & $\begin{array}{l}\text { dedicação dos } \\
\text { docentes }\end{array}$ & G3. Taxa de rotatividade de docentes nas instituições \\
\hline & $\begin{array}{l}\text { H-Diversificação } \\
\text { de IES, cursos e } \\
\text { áreas }\end{array}$ & $\begin{array}{l}\text { H1. Porcentagem dos discentes por tipos de cursos de graduação } \\
\text { (presencial, a distância, licenciaturas, tecnológicos, bacharelados) } \\
\text { H2. Porcentagem dos discentes por grandes áreas do conhecimento }\end{array}$ \\
\hline & $\begin{array}{l}\text { I-Internacionaliza- } \\
\text { ção dos discentes }\end{array}$ & $\begin{array}{l}\text { 11. Porcentagem de discentes estrangeiros em relação a todos os } \\
\text { discentes } \\
\text { 12. Porcentagem de discentes estudando no estrangeiro em relação } \\
\text { a todos os discentes }\end{array}$ \\
\hline & $\begin{array}{l}\text { J-Avaliação de } \\
\text { IES e cursos }\end{array}$ & gem dos cursos e instituições avaliadas externamente \\
\hline \multirow{15}{*}{$\begin{array}{l}\text { Resulta- } \\
\text { dos }\end{array}$} & \multirow{2}{*}{$\begin{array}{l}\text { K-Nível de êxito } \\
\text { dos alunos em } \\
\text { exames }\end{array}$} & $\begin{array}{l}\text { K1. Porcentagem de discentes com bom aproveitamento nos exames } \\
\text { de aprendizagem: geral e por disciplinas }\end{array}$ \\
\hline & & $\begin{array}{l}\text { K2. Porcentagem de cursos com boa avaliação externa: geral e por } \\
\text { tipo de cursos }\end{array}$ \\
\hline & \multirow{5}{*}{$\begin{array}{l}\text { L-Proporção de } \\
\text { matriculados } \\
\text { e taxas de esco- } \\
\text { larização }\end{array}$} & L1. Taxa de escolarização bruta da ES \\
\hline & & $\begin{array}{l}\text { L2. Número de discentes para cada grupo de } 100 \text { mil habitantes: geral } \\
\text { e por disciplina }\end{array}$ \\
\hline & & L3. Porcentagem de discentes que trabalham \\
\hline & & L4. Porcentagem de discentes por faixas-etárias \\
\hline & & L5. Taxa de evasão no primeiro ano de estudo na ES \\
\hline & \multirow{4}{*}{$\begin{array}{l}\text { M-Impactos no } \\
\text { desenvolvimento } \\
\text { econômico e } \\
\text { social }\end{array}$} & $\begin{array}{l}\text { M1. Taxa de empregabilidade de graduados até dois anos: geral e } \\
\text { por disciplinas }\end{array}$ \\
\hline & & $\begin{array}{l}\text { M2. Porcentagem de diplomados em educação superior no conjunto } \\
\text { da força de trabalho }\end{array}$ \\
\hline & & M3. Porcentagem de discentes envonvidos com P\&D \\
\hline & & $\begin{array}{l}\text { M4. Número de publicações científicas relevantes para cada grupo } \\
\text { de } 100 \text { docentes pesquisadores: geral e por grandes áreas do co- } \\
\text { nhecimento }\end{array}$ \\
\hline & \multirow{4}{*}{$\begin{array}{l}\mathrm{N}-\text { Equidade social } \\
\text { e regional }\end{array}$} & $\begin{array}{l}\text { N1. Relação entre o percentual da raça dos estudantes da ES e o } \\
\text { percentual da raça da população }\end{array}$ \\
\hline & & $\begin{array}{l}\text { N2. Relação entre o percentual de estudantes da ES de classes sociais } \\
\text { baixas e o percentual da população de classes sociais baixas }\end{array}$ \\
\hline & & $\begin{array}{l}\text { N3. Relação entre o percentual de estudantes da ES das regiões e o } \\
\text { percentual da população dessas regiões }\end{array}$ \\
\hline & & $\begin{array}{l}\text { N4. Porcentagem de cursos com bom aproveitamento nos exames de } \\
\text { aprendizagem por regiões do país }\end{array}$ \\
\hline
\end{tabular}

Fonte: Bertolin, 2007a.

Figura 1 - Sistema de Indicadores para a qualidade do Sesb 
e justificado de forma documental, também disponibiliza tabelas específicas (planilhas eletrônicas) para o estudo e desenvolvimento de pesquisas com os dados estatísticos levantados sobre a educação superior brasileira. No caso deste órgão, as informações e estatísticas disponíveis sobre IES, cursos, matrículas, vagas, ingressantes, concluintes, docentes etc. podem ser agrupadas em diferentes aspectos, tais como por categorias administrativas e organização acadêmica das IES, por regiões do país, por área do conhecimento dos cursos etc. Outra importante fonte de informação sobre a educação superior é a pesquisa realizada anualmente pelo IBGE nas residências conhecida por Pnad. No ano de 2002, por exemplo, a amostra incluiu aproximadamente $130 \mathrm{mil}$ casas, com informações de 385 mil pessoas representativas de toda população brasileira, excetuando-se apenas a zona rural da região Norte. Além dos dados e estatísticas disponibilizadas pelo MEC e o IBGE, para o desenvolvimento da medição dos indicadores do Sesb também foram utilizadas informações do Banco Central, CNPq, Ministério de Ciência e Tecnologia (MCT) e Seppir, muitas já tabuladas pelos próprios órgãos e publicadas ou disponíveis na rede mundial de computadores. Na internet, os dados e estatísticas sobre educação e educação superior podem ser encontrados principalmente nos endereços da Edudatabrasil do Inep (http://www.edudatabrasil.inep.gov.br/), dos Indicadores Nacionais de C\&T do MCT (http://ftp.mct.gov.br/estat/ascavpp/Default.htm), do Sidra - Sistema IBGE de recuperação Automática (http://www.sidra.ibge. gov.br/) e da fapesp.indica (http://www.fapesp.br/indicadores/). A maioria das medições dos indicadores demandou novos cruzamentos, relações ou agrupamentos entre dados e estatísticas dos diferentes órgãos, ou seja, novas elaborações, que possibilitaram o acompanhamento da evolução de aspectos de um SES com vistas à avaliação do desenvolvimento da qualidade do Sesb no período estudado.

\subsection{Indicadores de entradas}

\section{A1 - Investimentos do governo federal nas Ifes como percentual do PIB}

Como não existem informações detalhadas e confiáveis para o cálculo da porcentagem de todo o investimento (privado e estatal) em educação superior em relação ao PIB brasileiro no período em estudo (1994-2003), a verificação das despesas executadas pelas Ifes como porcentagem do PIB é uma das formas possíveis para a medição do investimento em educação superior. O gráfico da Figura 2 utiliza dados do MEC, sobre os orçamentos das Ifes, e do IBGE, sobre o PIB brasileiro, com vistas a verificar a evolução das despesas do governo fede- 


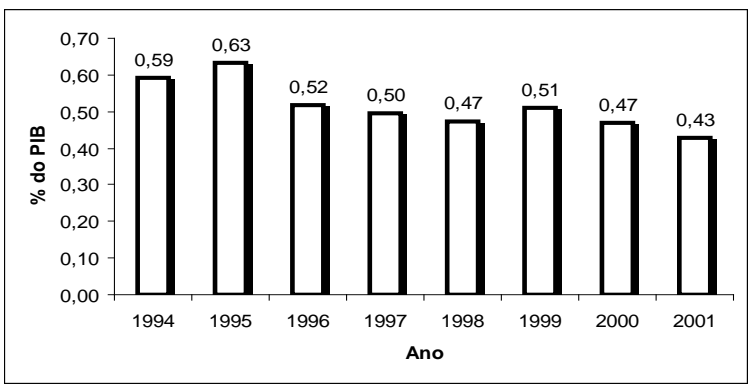

Figura 2 - Despesas executadas pelas Ifes com recursos do Tesouro como porcentagem do PIB no período 1994-2001

Fonte: Elaborado pelo autor a partir de BRASIL/MEC, 2002 e IPIB/IBGE, 2006.

ral e do MEC com as Ifes no período 1994-2001. Os gastos com servidores inativos foram retirados do cálculo por se considerar que tais valores não representam gastos ou investimentos com educação superior, mas que se referem ao montante vinculado à questão previdenciária. $\mathrm{O}$ gráfico demonstra que no intervalo de oito anos a porcentagem das despesas do MEC com as Ifes caiu de aproximadamente $0,6 \%$ para $0,4 \%$ do PIB, ou seja, especificamente no âmbito do financiamento do governo federal para a educação superior, no período 1994-2001 ocorreu redução na destinação de recursos como proporção do PIB nacional.

\section{A2 - Participação do governo federal nos investimentos do SFE}

\begin{tabular}{|l|l|l|l|l|l|}
\hline Ano & $\begin{array}{l}\text { Nro de } \\
\text { discentes }\end{array}$ & $\begin{array}{l}\text { Discentes } \\
\text { pagantes }\end{array}$ & $\begin{array}{l}\text { Financiamento } \\
\text { privado }\end{array}$ & $\begin{array}{l}\text { Financiamento } \\
\text { das IFES }\end{array}$ & $\begin{array}{l}\text { \% Financia- } \\
\text { mento Federal }\end{array}$ \\
\hline 1994 & 970584 & 873526 & $\mathrm{R} \$ 4.717 .038 .240,00$ & $\mathrm{R} \$ 8.820 .530 .328,34$ & $65 \%$ \\
\hline 1995 & 1059163 & 953247 & $\mathrm{R} \$ 5.147 .532 .180,00$ & $\mathrm{R} \$ 6.086 .440 .055,73$ & $54 \%$ \\
\hline 1996 & 1133102 & 1019792 & $\mathrm{R} \$ 5.506 .875 .720,00$ & $\mathrm{R} \$ 5.169 .603 .304,78$ & $48 \%$ \\
\hline 1997 & 1186433 & 1067790 & $\mathrm{R} \$ 5.766 .064 .380,00$ & $\mathrm{R} \$ 5.176 .273 .437,68$ & $47 \%$ \\
\hline 1998 & 1321229 & 1189106 & $\mathrm{R} \$ 6.421 .172 .940,00$ & $\mathrm{R} \$ 5.010 .927 .953,99$ & $44 \%$ \\
\hline 1999 & 1537923 & 1384131 & $\mathrm{R} \$ 7.474 .305 .780,00$ & $\mathrm{R} \$ 5.627 .070 .466,97$ & $43 \%$ \\
\hline 2000 & 1807219 & 1626497 & $\mathrm{R} \$ 8.783 .084 .340,00$ & $\mathrm{R} \$ 5.429 .805 .127,92$ & $38 \%$ \\
\hline 2001 & 2091529 & 1882376 & $\mathrm{R} \$ 10.164 .830 .940,00$ & $\mathrm{R} \$ 5.146 .722 .029,00$ & $34 \%$ \\
\hline 2002 & 2428258 & 2185432 & $\mathrm{R} \$ 11.801 .333 .880,00$ & & \\
\hline 2003 & 2750652 & 2475587 & $\mathrm{R} \$ 13.368 .168 .720,00$ & & \\
\hline
\end{tabular}

Figura 3 - Estimativa comparativa do financiamento privado e do governo federal das IES do Sistema Federal de Ensino no período 1994-2001

Fonte: Elaborado pelo autor a partir de BRASIL/MEC, 2002; INEP, 2004 e BRASIL/Banco Central, 2006b. 
O valor das mensalidades dos cursos privados de nível superior pode variar em função de muitos fatores, tais como status social dos cursos de graduação, localização regional das IES, existência de mercados competitivos nas regiões de abrangência das IES, perfil socioeconômico dos discentes, diversidade na oferta e nos descontos de créditos proporcionados aos discentes, entre outros fatores. Não obstante tais variações, a estimativa da evolução do financiamento privado no Sesb pode ser desenvolvida pelo estabelecimento de um valor de anuidade média por discente. Assim, ao se utilizar a anuidade média praticada pelo Fies no ano de 2001 de R \$ 5,4 mil (Schwartzman, 2002) e se descontar aproximadamente $10 \%$ do total dos discentes das IES privadas beneficiados com bolsas ou créditos, é possível demonstrar a tendência de ampliação do financiamento privado no Sistema Federal de Ensino - SFE. Trabalhando com as estimativas com valores resultantes da multiplicação da anuidade do Fies e o número total de alunos pagantes para o financiamento privado, a Figura 3 apresenta uma comparação entre esses valores e o financiamento estatal das Ifes no conjunto total de financiamento do SFE. Tal comparação demonstra a redução constante da participação dos recursos do governo federal no financiamento total do Sistema Federal de Ensino no período 1994-2001.

\section{A3 - Investimentos do governo federal nas Ifes por discentes}

\begin{tabular}{|r|r|r|r|r|r|}
\hline \multicolumn{1}{|l|}{ Ano } & \multicolumn{1}{|l|}{ Despesas executadas } & INPC & Valores deflacionados & \multicolumn{1}{l|}{$\begin{array}{l}\text { Nro de } \\
\text { discentes }\end{array}$} & $\begin{array}{l}\text { Investimento } \\
\text { por discente }\end{array}$ \\
\hline 1994 & $\mathrm{R} \$ 2.069 .963 .937,00$ & 277,28 & $\mathrm{R} \$ 8.820 .530 .328,34$ & 363543 & $\mathrm{R} \$ 24.262,69$ \\
\hline 1995 & $\mathrm{R} \$ 4.089 .250 .239,00$ & 20,05 & $\mathrm{R} \$ 6.086 .440 .055,73$ & 367531 & $\mathrm{R} \$ 16.560,34$ \\
\hline 1996 & $\mathrm{R} \$ 4.034 .943 .167,00$ & 8,77 & $\mathrm{R} \$ 5.196 .603 .304,78$ & 388978 & $\mathrm{R} \$ 13.359,63$ \\
\hline 1997 & $\mathrm{R} \$ 4.312 .842 .391,00$ & 4,26 & $\mathrm{R} \$ 5.176 .273 .437,68$ & 395833 & $\mathrm{R} \$ 13.076,91$ \\
\hline 1998 & $\mathrm{R} \$ 4.328 .721 .453,00$ & 2,47 & $\mathrm{R} \$ 5.010 .927 .953,99$ & 408640 & $\mathrm{R} \$ 12.262,45$ \\
\hline 1999 & $\mathrm{R} \$ 4.966 .961 .309,00$ & 8,13 & $\mathrm{R} \$ 5.627 .070 .466,97$ & 442562 & $\mathrm{R} \$ 12.714,76$ \\
\hline 2000 & $\mathrm{R} \$ 5.163 .374 .979,00$ & 5,16 & $\mathrm{R} \$ 5.429 .805 .127,92$ & 482750 & $\mathrm{R} \$ 11.247,65$ \\
\hline 2001 & $\mathrm{R} \$ 5.146 .722 .029,00$ & & $\mathrm{R} \$ 5.146 .722 .029,00$ & 502960 & $\mathrm{R} \$ 10.232,87$ \\
\hline
\end{tabular}

Figura 4 - Despesas executadas pelas Ifes com recursos do Tesouro por discente no período 1994-2001

Fonte: Elaborado pelo autor a partir de BRASIL/MEC, 2002; INEP, 2004 e BRASIL/Banco Central, 2006b.

Outro importante indicador para acompanhar e avaliar o financimento de um SES é o valor investido por discente. No caso do Brasil, a verificação da relação entre as despesas executas pelas Ifes com recursos do Tesouro da União pela quantidade total de discentes das Ifes é uma importante alternativa para medição 
de tal indicador visto que existem limitações de informações detalhadas sobre financiamento. A Figura 4 utiliza dados do MEC, sobre os orçamentos das Ifes; do Inep, sobre a quantidade de alunos nas Ifes, e do Banco Central do Brasil, sobre o índice nacional de preços ao consumidor (INPC), com vistas a verificar a evolução das despesas do governo federal e do MEC por discentes das Ifes no período 1994-2001. Nesse cálculo, os gastos com servidores inativos também foram retirados e as despesas executadas anualmente foram deflacionadas pelo INPC para padronizar em valores reais do ano de 2001. A figura demonstra uma relevante queda nos valores das despesas executadas pelas Ifes por cada discente no período 1994-2001.

\section{B1 - Investimentos do governo federal em P\&D na educação superior}

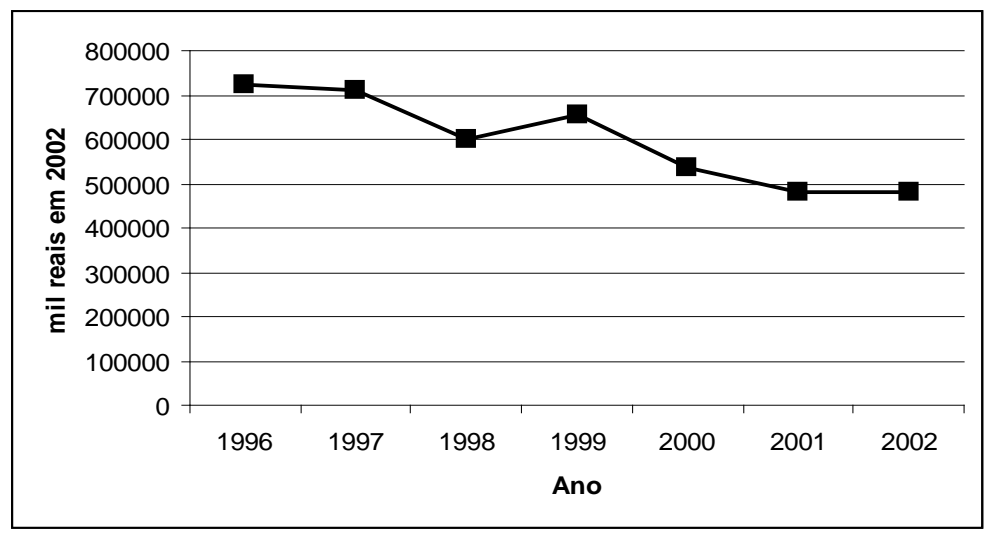

Figura 5 - Dispêndio do governo federal em P\&D com o MEC no período 1996-2002

Fonte: BRASIL/MCT, 2004.

O indicador de investimento em $\mathrm{P} \& \mathrm{D}$ possui grande importância porque aborda aspectos relacionados à relevância da educação superior para o desenvolvimento científico e tecnológico de um país. Levantamentos recentes do MCT apontam para a tendência de queda do investimento brasileiro em P\&D como porcentagem do PIB. No ano de 2001, o investimento em P\&D era de 1,02\% do PIB; nos anos subseqüentes, ocorreram reduções até se chegar ao de 2003, com $0,95 \%$ do PIB. A Figura 5 confirma tal tendência ao demonstrar a redução do investimento do governo federal em P\&D com o Ministério da Educação. Em valores atualizados por reais de 2002, a figura apresenta a redução do investimento do governo federal de, aproximadamente, 700 milhões em 1996 
para menos de 500 milhões em 2002. Tal constatação tem grande relevância na análise dos investimentos em $\mathrm{P} \& \mathrm{D}$ porque mais de $90 \%$ dos gastos nessa área na educação superior são provenientes de recursos estatais.

D1a- Quantidade de discentes por cada docente com título de doutor no Sesb

\begin{tabular}{|c|c|c|c|c|}
\hline Ano & IFES & Estaduais e Municipais & Privadas & Sesb \\
\hline 1994 & 40 & 42 & 217 & 78 \\
\hline 1995 & 37 & 42 & 218 & 77 \\
\hline 1996 & 38 & 41 & 207 & 78 \\
\hline 1997 & 33 & 42 & 183 & 72 \\
\hline 1998 & 31 & 38 & 175 & 68 \\
\hline 1999 & 30 & 36 & 161 & 68 \\
\hline 2000 & 29 & 35 & 146 & 66 \\
\hline 2001 & 29 & 32 & 137 & 66 \\
\hline 2002 & 28 & 36 & 138 & 69 \\
\hline 2003 & 27 & 37 & 138 & 69 \\
\hline
\end{tabular}

Figura 6 - Quantidade de discentes por docente com título de doutor nas Ifes, nas IES estaduais/municipais, e nas IES privadas e no Sesb no período 1994-2003

Fonte: Elaborado pelo autor a partir de INEP, 2005b.

Outros indicadores que propiciam avaliar aspectos de entradas de um SES são os que medem a relação entre as quantidades de discentes por docente. As medições da quantidade de discentes por docente podem ser analisadas segundo distintas perspectivas: (i) como um aspecto específico de qualidade, visto que, quanto menor é a relação de discentes por docente (ou por docente com alta titulação), maiores são as possibilidades de atendimento qualificado aos alunos; e, por outro lado, (ii) como um aspecto de eficiência de um SES, visto que, quanto maior é a relação de discentes por docente, menores serão os custos para a manutenção do sistema. Não obstante tais divergências, a verificação da razão de discentes por docentes com título de doutor é uma importante medição porque aborda múltiplos aspectos, tais como qualidade na formação docente e potencialidade de envolvimento discente em investigação e pesquisas. A Figura 6 demonstra que todas as redes de IES de educação superior do Brasil tiveram melhorias na evolução da relação discentes por docentes com título de doutor no período 1994-2003. Porém, tal indicador apresenta nos três últimos anos do período estudado uma tendência de estabilização em nível de Sesb e 
de incipiente regressão na rede privada. Tal tendência é especialmente preocupante visto que a diferença entre os resultados desse indicador no ano de 2003 entre as redes privadas (138 alunos por professor com doutorado) e as Ifes (27 alunos por professor com doutorado) é muito grande, bem como a proporção de 5 para 1 entre discentes/doutor da rede privada e das Ifes permaneceu quase a mesma no período 1994-2003.

D1b- Quantidade de discentes por cada docente

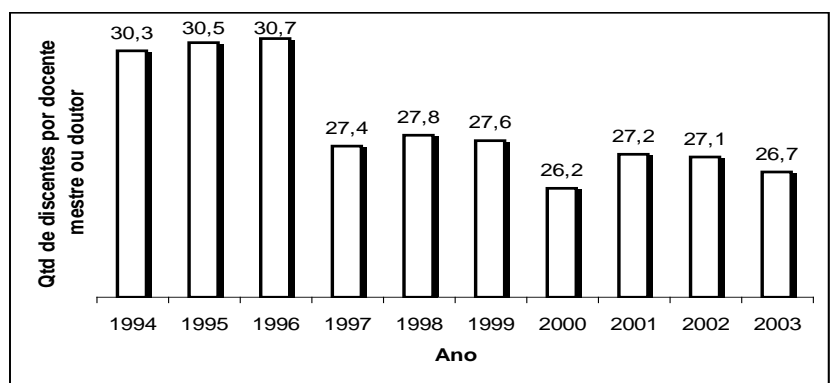

Figura 7 - Evolução da razão de discentes por docente com título de mestre ou doutor no Sesb no período 1994-2003

Fonte: Elaborado pelo autor a partir de INEP, 2005b.

Quando considerados os docentes com títulos de mestre e doutor, a evolução do indicador discentes por cada docente titulado em nível de Sesb apresenta um melhoria menos significativa e uma clara estagnação após 1996, ou seja, na maior parte do período estudado não ocorreram melhorias contínuas desse indicador (Figura 7).

D2- Quantidade de discentes por cada docente no Sesb

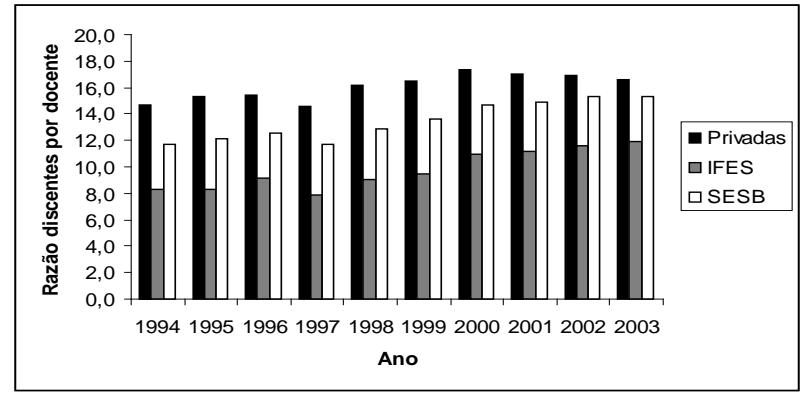

Figura 8 - Quantidade de discentes por docente nas privadas, nas IFES e no Sesb no período 1994-2003

Fonte: Elaborado pelo autor a partir de INEP, 2005b. 
A Figura 8 demonstra que a pequena evolução da quantidade de discentes por docente (independentemente de titulação) no Sesb (de 12 para 15 alunos por professor) durante o período 1994-2003 deve-se, fundamentalmente, à ampliação de tal relação ocorrida nas Ifes, que avançou de 8 para 12, ao passo que na rede privada praticamente não houve mudanças.

\subsection{Indicadores de processo}

G1- Porcentagem de docentes com dedicação integral e parcial no Sesb

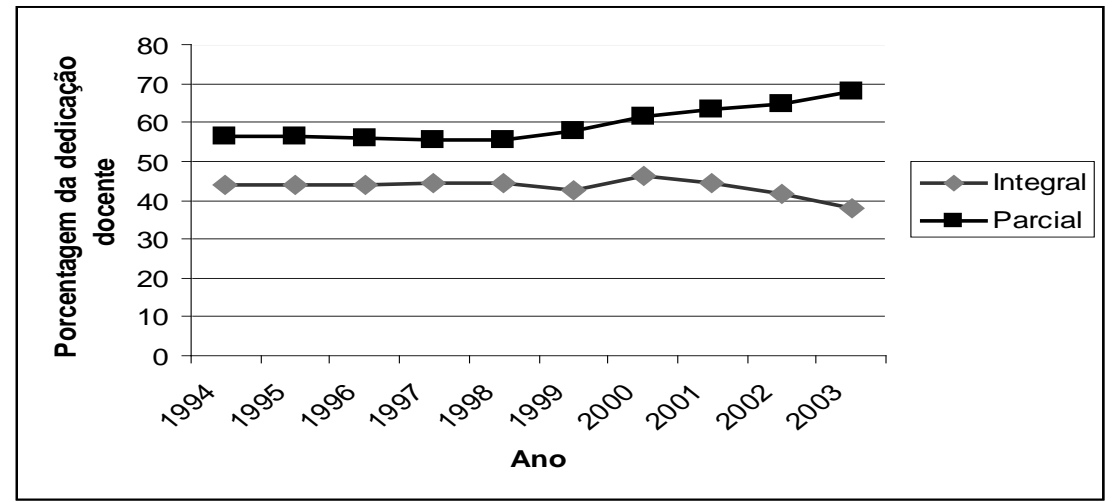

Figura 9 - Evolução da porcentagem de docentes com dedicação integral e parcial do Sesb no período 1994-2003

Fonte: Elaborado pelo autor a partir de INEP, 2005b.

O tempo dedicado pelos docentes para as IES é um dos mais importantes indicadores de processo dos SES. Docentes com dedicação exclusiva para a educação superior geralmente apresentam maior envolvimento com as questões acadêmicas, maior comprometimento com as IES e, potencialmente, detêm maior titulação e envolvimento com projetos de investigação. Por outro lado, quanto menor a dedicação dos docentes para a educação superior, menor a tendência de envolvimento com as questões fundamentais das IES e com suas dimensões acadêmicas. A Figura 9 demonstra que a porcentagem de docentes com dedicação exclusiva diminuiu e com dedicação parcial aumentou no conjunto total do Sesb no período 1994-2003. 
H2- Porcentagem dos discentes por grandes áreas do conhecimento no Sesb

\begin{tabular}{|l|r|r|r|r|r|r|r|r|r|r|}
\hline Área do Conhecimento & 1994 & 1995 & 1996 & 1997 & 1998 & $\mathbf{1 9 9 9}$ & $\mathbf{2 0 0 0}$ & $\mathbf{2 0 0 1}$ & $\mathbf{2 0 0 2}$ & $\mathbf{2 0 0 3}$ \\
\hline Educação, Humanidades e Artes & $17 \%$ & $17 \%$ & $16 \%$ & $16 \%$ & $16 \%$ & $17 \%$ & $25 \%$ & $25 \%$ & $23 \%$ & $25 \%$ \\
\hline Ciência Sociais, Negócios e Direito & $42 \%$ & $43 \%$ & $43 \%$ & $44 \%$ & $44 \%$ & $44 \%$ & $42 \%$ & $42 \%$ & $43 \%$ & $42 \%$ \\
\hline Ciências, Matemática e Computação & $13 \%$ & $13 \%$ & $14 \%$ & $13 \%$ & $14 \%$ & $14 \%$ & $9 \%$ & $9 \%$ & $9 \%$ & $9 \%$ \\
\hline Engenharia, Produção e Construção & $11 \%$ & $10 \%$ & $10 \%$ & $10 \%$ & $9 \%$ & $9 \%$ & $9 \%$ & $8 \%$ & $8 \%$ & $8 \%$ \\
\hline Agricultura e Veterinária & $3 \%$ & $2 \%$ & $2 \%$ & $3 \%$ & $3 \%$ & $3 \%$ & $2 \%$ & $2 \%$ & $2 \%$ & $2 \%$ \\
\hline Saúde e Bem-Estar Social & $13 \%$ & $13 \%$ & $13 \%$ & $13 \%$ & $14 \%$ & $14 \%$ & $12 \%$ & $12 \%$ & $13 \%$ & $12 \%$ \\
\hline Serviços & $1 \%$ & $1 \%$ & $1 \%$ & $1 \%$ & $1 \%$ & $0 \%$ & $2 \%$ & $2 \%$ & $2 \%$ & $2 \%$ \\
\hline Outras & $0 \%$ & $0 \%$ & $0 \%$ & $0 \%$ & $0 \%$ & $0 \%$ & $0 \%$ & $0 \%$ & $0 \%$ & $0 \%$ \\
\hline
\end{tabular}

Figura 10 - Evolução da porcentagem de discentes por grandes áreas do conhecimento do Sesb no período 1994-2003

Fonte: Elaborado pelo autor a partir de INEP, 2004.

*obs: A partir do ano de 2000 os cursos de licenciatura passaram a integrar a área de educação.

A verificação da distribuição dos discentes nas grandes áreas do conhecimento, além de contribuir na análise sobre a evolução da diversificação de um SES, possibilita o desenvolvimento de análises acerca da adequação dos cursos existentes diante da realidade social e econômica de um país. Assim, pela verificação da maior ou menor quantidade de discentes matriculados em determinadas áreas do conhecimento, os governos podem redirecionar suas políticas para a educação superior, conforme as necessidades imediatas do país ou de acordo com os planos de desenvolvimento de médio e longo prazos. A Figura 10 demonstra que no período 1994-2003 não ocorreu nenhuma alteração substancial na distribuição percentual das matrículas discentes no Sesb. Não obstante as profundas mudanças socioculturais (ex: a emergências das TIC) e econômicas (ex: globalização e economia do conhecimento) que o mundo sofreu no período, a análise do indicador de matrículas por áreas do conhecimento do Sesb permite verificar que não ocorreram as necessárias (ex: engenharias e ciência da computação) mudanças nas preferências das áreas do conhecimento por parte dos discentes. 
I1- Quantidade de discentes de mestrado

e doutorado para cada bolsista no exterior

\begin{tabular}{|c|c|c|c|c|c|}
\hline Ano & Mestrandos & Doutorandos & Cnpq & Capes & Razão \\
\hline 1996 & 41928 & 20924 & 1601 & 1300 & 22 \\
\hline 1997 & 44015 & 22935 & 1076 & 1404 & 27 \\
\hline 1998 & 50816 & 26828 & 792 & 1349 & 36 \\
\hline 1999 & 57044 & 29998 & 595 & 1259 & 47 \\
\hline 2000 & 63614 & 33004 & 562 & 1210 & 55 \\
\hline 2001 & 64906 & 35102 & 705 & 1279 & 50 \\
\hline 2002 & 65044 & 37400 & 707 & 1253 & 52 \\
\hline
\end{tabular}

Figura 11 - Quantidade de discentes de mestrado e doutorado no Brasil para cada bolsista no exterior no período 1996-2002

Fonte: Elaborado pelo autor a partir de CAPES, 2004; CNPQ, 2006 e BRASIL/MCT, 2004.

O intercâmbio de conhecimento técnico, científico e tecnológico entre os países é uma prática que ganhou relevância nas últimas duas décadas em virtude da globalização e do aumento da competitividade em nível mundial. Nesse contexto, o nível de internacionalização da educação superior torna-se fator fundamental para o desenvolvimento cultural, científico e econômico dos países. Uma das formas possíveis de se medir o nível de internacionalização da educação superior brasileira é pela quantidade de bolsas de mestrado, doutorado, doutorado-sanduíche e pós-doutorado concedidas pela Capes e pelo CNPq. A Figura 11 demonstra que no período de 1996-2002 a quantidade de alunos de mestrado e doutorado por bolsa concedida para estudo no exterior mais do que dobrou, ou seja, nesse aspecto pode-se dizer que o nível de internacionalização dos discentes de pós-graduação sofreu uma significativa redução.

Independentemente do matiz conceitual e da ênfase operacional, a existência de um sistema de avaliação das IES e dos cursos de graduação de um SES é importante para o acompanhamento e desenvolvimento do sistema, bem como para o suporte na elaboração de políticas públicas. No Brasil, a avaliação das instituições teve início com o Paiub que se baseava no princípio de adesão voluntária; em 1996 deu-se início à avaliação de cursos de graduação em larga escala, abrangendo 616 cursos. A Figura 12 demonstra claramente o significativo aumento no número de cursos submetidos à avaliação externa através do ENC (Provão) no período 1996-2003. 
AVALIAÇÃO DA EDUCAÇÃO SUPERIOR BRASILEIRA: RELEVÂNCIA, DIVERSIDADE, EQUIDADE E EFICẢCIA DO SISTEMA EM TEMPOS DE MERCANTILIZAÇÃO

J1- Quantidade de cursos de graduação avaliados pelo ENC (Provão)

\begin{tabular}{|c|c|c|c|c|c|c|c|c|}
\hline Área & 1996 & 1997 & 1998 & 1999 & 2000 & 2001 & 2002 & 2003 \\
\hline Administração & 335 & 354 & 391 & 431 & 451 & 498 & 614 & 746 \\
\hline Direito & 179 & 196 & 212 & 229 & 257 & 274 & 298 & 333 \\
\hline Engenharia Civil & 102 & 106 & 110 & 112 & 118 & 125 & 128 & 134 \\
\hline Engenharia Química & & 44 & 47 & 48 & 50 & 51 & 51 & 50 \\
\hline Medicina Veterinária & & 37 & 39 & 43 & 50 & 59 & 76 & 83 \\
\hline Odontologia & & 85 & 86 & 87 & 93 & 104 & 113 & 127 \\
\hline Engenharia Elétrica & & & 81 & 84 & 87 & 92 & 96 & 111 \\
\hline Jornalismo & & & 84 & 92 & 97 & 113 & 131 & 155 \\
\hline Letras & & & 369 & 382 & 406 & 432 & 472 & 510 \\
\hline Matemática & & & 291 & 305 & 322 & 358 & 358 & 379 \\
\hline Economia & & & & 187 & 189 & 187 & 190 & 201 \\
\hline Engenharia Mecânica & & & & 70 & 73 & 74 & 78 & 83 \\
\hline Medicina & & & & 81 & 81 & 83 & 87 & 91 \\
\hline Agronomia & & & & & 70 & 73 & 74 & 82 \\
\hline Biologia & & & & & 238 & 274 & 288 & 302 \\
\hline Física & & & & & 80 & 83 & 82 & 88 \\
\hline Psicologia & & & & & 117 & 123 & 136 & 156 \\
\hline Química & & & & & 109 & 113 & 116 & 132 \\
\hline Farmácia & & & & & & 86 & 108 & 124 \\
\hline Pedagogia & & & & & & 499 & 606 & 705 \\
\hline Arquitetura e Urbanismo & & & & & & & 96 & 108 \\
\hline Ciências contábeis & & & & & & & 408 & 454 \\
\hline Enfermagem & & & & & & & 144 & 161 \\
\hline História & & & & & & & 281 & 287 \\
\hline Fonoaudiologia & & & & & & & & 69 \\
\hline Geografia & & & & & & & & 226 \\
\hline Total & 616 & 822 & 1710 & 2151 & 2888 & 3701 & 5031 & 5897 \\
\hline Percentual & $9 \%$ & $13 \%$ & $25 \%$ & $24 \%$ & $27 \%$ & $30 \%$ & $35 \%$ & $36 \%$ \\
\hline
\end{tabular}

Figura 12 - Quantidade de cursos de graduação avaliados pelo ENC (Provão) no período 1996-2003

Fonte: Elaborado pelo autor a partir de INEP, 2003 e INEP, 2006 b. 


\subsection{Indicadores de resultados}

K1- Porcentagem de cursos das Ifes

e da rede privada com conceitos A ou B no Provão

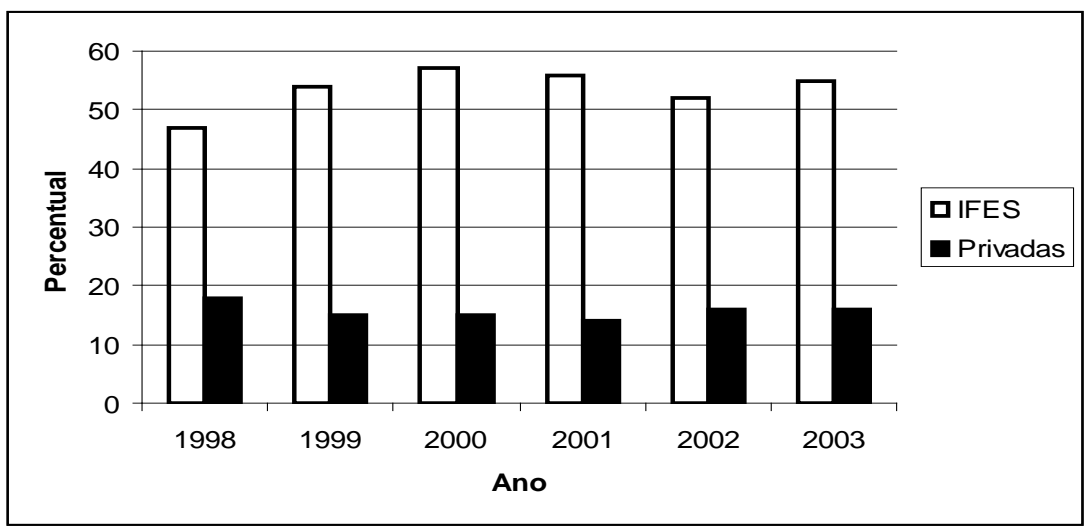

Figura 13 - Evolução da porcentagem de cursos com conceitos A ou B no Provão nas Ifes e na rede privada no período 1998-2003

Fonte: Elaborado pelo autor a partir de INEP, 2003 e INEP, 2006b.

A comparação entre os conceitos gerais obtidos no Provão pelos diversos cursos a cada ano não é possível pelas próprias fórmulas de cálculo dos conceitos utilizadas (que tendem a estabilidade geral de desempenho) e por que durante o período de realização do ENC ocorreram alterações na forma de cálculo dos conceitos. A Figura 13 permite a identificação dos cursos/áreas que foram sendo agregadas a cada ano de realização do ENC. Nas primeiras edições os resultados eram interpretados segundo ordenação dos desempenhos - média geral dos graduandos do curso -, a partir da qual eram determinados cinco grupos, sendo prefixado o percentual de integrantes de cada um dos grupos. Posteriormente, o critério de atribuição dos conceitos aos cursos avaliados foi redefinido e passou a levar em conta a distribuição geral dos desempenhos dos cursos. Dessa forma, a realização de comparação dos conceitos do ENC deve se limitar a análises gerais, tais como entre as redes que compõem o Sesb (Ifes, sistemas estaduais e rede privada). A Figura 14 demonstra a significativa diferença entre as porcentagens dos cursos das Ifes e da rede privada com conceitos A ou B. A Figura, baseada em amostragem, detalha a diferença de desempenho das diferentes redes no Provão, que, não obstante a inclusão de 
novos cursos e a mudança do cálculo, permaneceu praticamente inalterada no período 1998-2003.

\begin{tabular}{|c|c|c|c|c|c|c|c|}
\hline \multicolumn{4}{|c|}{1998} & \multicolumn{4}{|c|}{1999} \\
\hline$A+B$ & $C$ & $D+E$ & & $A+B$ & $\mathrm{C}$ & $D+E$ & \\
\hline $47 \%$ & $27 \%$ & $26 \%$ & IFES & $54 \%$ & $33 \%$ & $12 \%$ & IFES \\
\hline $31 \%$ & $38 \%$ & $31 \%$ & Est/Munic & $31 \%$ & $37 \%$ & $32 \%$ & Est/Munic \\
\hline $18 \%$ & $48 \%$ & $34 \%$ & Privadas & $15 \%$ & $46 \%$ & $39 \%$ & Privadas \\
\hline $32 \%$ & $38 \%$ & $30 \%$ & Sesb & $33 \%$ & $39 \%$ & $28 \%$ & Sesb \\
\hline \multicolumn{4}{|c|}{2000} & \multicolumn{4}{|c|}{2001} \\
\hline$A+B$ & $C$ & $D+E$ & & $A+B$ & C & $D+E$ & \\
\hline $57 \%$ & $28 \%$ & $15 \%$ & IFES & $56 \%$ & $30 \%$ & $14 \%$ & IFES \\
\hline $30 \%$ & $38 \%$ & $33 \%$ & Est/Munic & $27 \%$ & $43 \%$ & $30 \%$ & Est/Munic \\
\hline $15 \%$ & $49 \%$ & $35 \%$ & Privadas & $14 \%$ & $47 \%$ & $40 \%$ & Privadas \\
\hline $34 \%$ & $38 \%$ & $28 \%$ & Sesb & $32 \%$ & $40 \%$ & $28 \%$ & Sesb \\
\hline \multicolumn{4}{|c|}{2002} & \multicolumn{4}{|c|}{2003} \\
\hline$A+B$ & $\mathrm{C}$ & $D+E$ & & $A+B$ & $\mathrm{C}$ & $D+E$ & \\
\hline $52 \%$ & $32 \%$ & $16 \%$ & IFES & $55 \%$ & $29 \%$ & $16 \%$ & IFES \\
\hline $29 \%$ & $34 \%$ & $37 \%$ & Est/Munic & $30 \%$ & $39 \%$ & $31 \%$ & Est/Munic \\
\hline $16 \%$ & $48 \%$ & $36 \%$ & Privadas & $16 \%$ & $51 \%$ & $33 \%$ & Privadas \\
\hline $32 \%$ & $38 \%$ & $30 \%$ & Sesb & $34 \%$ & $40 \%$ & $27 \%$ & Sesb \\
\hline
\end{tabular}

Figura 14 - Evolução da porcentagem de cursos das Ifes, dos sistemas estaduais, da rede privada e do Sesb por conceitos no período 1998-2003

Fonte: Elaborado pelo autor a partir de INEP, 2003 e INEP, 2006 b.

L1- Taxa de escolarização líquida da educação superior brasileira

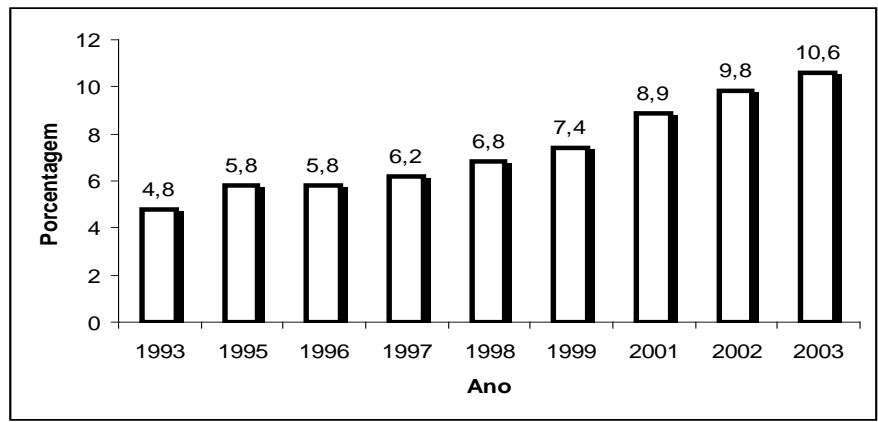

Figura 15 - Evolução da taxa de escolarização líquida na educação superior brasileira no período 1993-2003

Fonte: Elaborado pelo autor a partir de BRASIL/Seppir, 2006a.

*obs: Exclusive a população rural de Rondônia, Roraima, Amapá, Amazonas, Pará e Acre. 
A taxa de atendimento num determinado nível de educação de um país pode ser verificada de duas maneiras: taxa de escolarização líquida ou taxa de escolarização bruta. A taxa de escolarização líquida indica o percentual da população em determinada faixa etária que se encontra matriculada no nível de ensino adequado à sua idade. A taxa de escolarização bruta permite que se compare o total da matrícula num dado nível de ensino com a população na faixa etária adequada a esse nível. Considerando-se a população entre 18 e 24 como a adequada para a educação superior, a taxa de atendimento no Brasil aumentou em ambos indicadores nos últimos tempos. A taxa de escolarização bruta da educação superior cresceu de 8,1\%, em 1991, para 15,1\%, em 2002 (INEP, 2004). A Figura 15 demonstra o crescimento do percentual da população com idade entre 18 e 24 anos matriculada na educação superior brasileira no período 1993-2004, ou seja, apresenta o crescimento da taxa de escolarização líquida da educação superior no período 1993-2004. Não obstante tais crescimentos, o Brasil continua com taxas de atendimento na educação superior inferiores às de países como Argentina (48\% de taxa bruta em 1999), Bolívia (36\% de taxa bruta em 2002), Portugal (50\% de taxa bruta em 2002), Coréia (78\% de taxa bruta em 2002) e EUA (73\% de taxa bruta em 2002) (INEP, 2004).

L5- Porcentagem de concluintes em relação a ingressantes 4 anos antes no Sesb

\begin{tabular}{|c|c|c|c|c|}
\hline \multicolumn{2}{|c|}{ Ingressantes } & \multicolumn{2}{c|}{ Concluintes } \\
\hline Ano & Quantidade & Ano & Quantidade & Porcentagem \\
\hline 1993 & 439801 & 1996 & 260224 & $59 \%$ \\
\hline 1994 & 463240 & 1997 & 274384 & $59 \%$ \\
\hline 1995 & 510377 & 1998 & 300761 & $59 \%$ \\
\hline 1996 & 513842 & 1999 & 324734 & $63 \%$ \\
\hline 1997 & 573900 & 2000 & 352305 & $61 \%$ \\
\hline 1998 & 651353 & 2001 & 395988 & $61 \%$ \\
\hline 1999 & 787638 & 2002 & 466260 & $59 \%$ \\
\hline 2000 & 897557 & 2003 & 528223 & $59 \%$ \\
\hline
\end{tabular}

Figura 16 - Evolução da porcentagem de concluintes em relação aos discentes que ingressaram 4 anos antes no Sesb no período 1996-2003

Fonte: Elaborado pelo autor a partir de INEP, 2005b. 
A questão do atendimento da educação superior ultrapassa os aspectos relativos ao acesso visto que as taxas de desistência e evasão podem impactar o resultado final dos níveis de diplomação da população de um determinado país. Dessa forma, a verificação da efetiva conclusão da graduação torna-se um importante indicador dos resultados de um SES. A Figura 16 demonstra que no Sesb, no período 1996-2003, não ocorreram mudanças importantes no percentual de concluintes em relação aos discentes que ingressaram quatro anos antes, que é o tempo médio de duração de um curso de graduação no Brasil.

M2- Porcentagem da população com diploma superior da PEA no Brasil

\begin{tabular}{|l|r|r|r|r|r|r|r|r|r|}
\hline Ano & 1993 & 1995 & 1996 & 1997 & 1998 & $\mathbf{1 9 9 9}$ & $\mathbf{2 0 0 1}$ & $\mathbf{2 0 0 2}$ & $\mathbf{2 0 0 3}$ \\
\hline PEA & 73.549 & 77.116 & 76.225 & 78.693 & 80.592 & 83.266 & 85.224 & 88.242 & 90.161 \\
\hline Graduados & 3.964 & 4.435 & 4.499 & 4.882 & 5.065 & 5.294 & 5.736 & 6.310 & 6.684 \\
\hline Porcentagem & $5,4 \%$ & $5,8 \%$ & $5,9 \%$ & $6,2 \%$ & $6,3 \%$ & $6,4 \%$ & $6,7 \%$ & $7,2 \%$ & $7,4 \%$ \\
\hline
\end{tabular}

Figura 17 - Evolução da porcentagem da população economicamente ativa com diploma superior no Brasil no período 1993-2003

Fonte: Elaborado pelo autor a partir de BRASIL/MCT, 2004.

*obs: (a) Número de PEA e graduados em mil pessoas; (b) Exclusive a população rural de Rondônia, Roraima, Amapá, Amazonas, Pará e Acre.

A participação de pessoas com diploma de nível superior no conjunto da força de trabalho de um país indica em que medida o SES está respondendo e, por conseguinte, contribuindo com a produção e o desenvolvimento econômico, ou seja, a medição da porcentagem da PEA com diploma superior é um importante indicador de resultados de um SES. A Figura 17 demonstra que no período estudado ocorreram avanços na porcentagem da população economicamente ativa com diploma superior no Brasil, saindo de 5,4\%, em 1993, para 7,4\%, em 2003. 
M3- Quantidade de pessoas inseridas

em ocupação técnico-científica por publicação

\begin{tabular}{|l|r|r|r|r|r|}
\hline Ano & 1998 & $\mathbf{1 9 9 9}$ & $\mathbf{2 0 0 1}$ & $\mathbf{2 0 0 2}$ & $\mathbf{2 0 0 3}$ \\
\hline $\begin{array}{l}\text { Pessoas com escola- } \\
\text { ridade superior inse- } \\
\text { ridas em ocupações } \\
\text { técnico-científicas }\end{array}$ & 3.375 .000 & 3.433 .000 & 3.782 .000 & 4.706 .000 & 4.914 .000 \\
\hline $\begin{array}{l}\text { Publicação de artigos } \\
\text { especializados de cir- } \\
\text { culação internacional }\end{array}$ & 20.950 & 23.715 & 26.910 & 29.271 & 30.386 \\
\hline $\begin{array}{l}\text { Quantidade de pes- } \\
\text { soas inseridas em ocu- } \\
\text { pação técnico-científi- } \\
\text { cas por cada publica- } \\
\text { ção internacional }\end{array}$ & 161 & 145 & & & \\
\hline
\end{tabular}

Figura 18 - Quantidade de pessoas inseridas em ocupação técnico-científica por publicação internacional no Brasil no período 1998-2003

Fonte: Elaborado pelo autor a partir de BRASIL/MCT, 2004.

Uma das formas mais importantes de um SES contribuir com o desenvolvimento e a autonomia científica e tecnológica de um país é pela pesquisa e investigação. Para a verificação do nível de desenvolvimento da P\&D de um SES faz-se necessário acompanhar o número de publicações científicas relevantes em relação à quantidade de docentes que desenvolvem pesquisas. A Figura 18 demonstra que no período 1998-2003 não ocorreu, em nível de Brasil, nenhum aumento significativo na relação entre a quantidade de pessoas com escolaridade superior inseridas em ocupação técnico-científica e o número de publicações de artigos especializados de circulação internacional.

N1- Comparação entre as taxas de escolarização líquida das populações negra e branca na educação superior

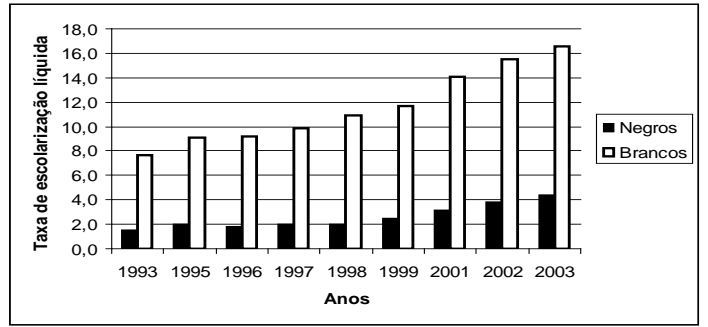

Figura 19 - Comparação entre as taxas de escolarização líquida das populações negra e branca na educação superior brasileira no período 1993-2003

Fonte: Elaborado pelo autor a partir de BRASIL/Seppir, 2006a.

*obs: (a) A população negra é composta de pardos e pretos; (b) Exclusive a população rural de Rondônia, Roraima, Amapá, Amazonas, Pará e Acre. 
O nível de eqüidade de um SES pode ser medido pelo atendimento proporcionado às minorias ou às parcelas da população em situação desfavorável do ponto de vista social e econômico. Um dos fatores principais na questão da eqüidade está relacionado ao atendimento igualitário para as diferentes raças, etnias ou classes sociais. A Figura 19 demonstra uma melhora de aproximadamente 2,9 pontos percentuais na evolução da taxa de escolarização líquida da população negra na educação superior brasileira no período 1993-2003 (de 1,5 para 4,4), ao passo que entre a população branca tal evolução foi de 8,9 pontos percentuais - de 7,7 para 16,6. No período estudado, o crescimento da taxa de atendimento da raça negra foi de $193 \%$ e da raça branca, de $115 \%$, o que indica um avanço maior para a raça negra. Entretanto, a diferença entre as taxas líquidas de escolarização da população negra e branca aumentou de 6,2 pontos percentuais no ano de 1993 para 12,2 pontos percentuais em 2003, ou seja, o ritmo de avança do indicador para a raça com menores taxas de atendimento (negra) parece ter sido insuficiente. Dessa forma, pode-se considerar que esse indicador não apresentou melhorias significativas no período estudado.

N3- Evolução da relação entre porcentagem de discentes e de população das regiões do Brasil

\begin{tabular}{|c|c|c|c|c|c|c|c|c|c|}
\hline Região & & 1995 & 1996 & 1997 & 1998 & 1999 & 2001 & 2002 & 2003 \\
\hline \multirow{3}{*}{ Norte } & $\%$ de estudantes do país & 3,8 & 4,1 & 4,0 & 4,0 & 4,0 & 4,7 & 5,5 & 5,9 \\
\hline & \% da população do país & 4,8 & 4,8 & 4,9 & 5,0 & 5,0 & 5,7 & 6,0 & 6,0 \\
\hline & Relação & 0,8 & 0,9 & 0,8 & 0,8 & 0,8 & 0,8 & 0,9 & 1,0 \\
\hline \multirow{3}{*}{ Nordeste } & $\%$ de estudantes do país & 15,3 & 15,0 & 14,9 & 14,6 & 15,1 & 15,2 & 15,6 & 16,1 \\
\hline & \% da população do país & 29,6 & 29,6 & 29,1 & 29,0 & 28,9 & 28,6 & 28,4 & 28,4 \\
\hline & Relação & 0,5 & 0,5 & 0,5 & 0,5 & 0,5 & 0,5 & 0,5 & 0,6 \\
\hline \multirow{3}{*}{$\begin{array}{l}\text { Centro- } \\
\text { Oeste }\end{array}$} & \% de estudantes do país & 7,0 & 7,2 & 7,5 & 7,7 & 7,9 & 8,6 & 9,3 & 9,5 \\
\hline & \% da população do país & 6,8 & 6,8 & 6,9 & 7,0 & 7,0 & 7,0 & 7,1 & 7,1 \\
\hline & Relação & 1,0 & 1,1 & 1,1 & 1,1 & 1,1 & 1,2 & 1,3 & 1,3 \\
\hline \multirow{3}{*}{ Sudeste } & $\%$ de estudantes do país & 55,3 & 55,0 & 54,1 & 54,0 & 53,1 & 51,7 & 50,2 & 49,3 \\
\hline & \% da população do país & 43,6 & 43,6 & 43,7 & 43,7 & 43,7 & 43,5 & 43,5 & 43,5 \\
\hline & Relação & 1,3 & 1,3 & 1,2 & 1,2 & 1,2 & 1,2 & 1,2 & 1,1 \\
\hline \multirow{3}{*}{ Sul } & $\%$ de estudantes do país & 18,6 & 18,7 & 19,5 & 19,7 & 20,0 & 19,8 & 19,5 & 19,2 \\
\hline & \% da população do país & 15,2 & 15,2 & 15,3 & 15,3 & 15,3 & 15,2 & 15,0 & 15,0 \\
\hline & Relação & 1,2 & 1,2 & 1,3 & 1,3 & 1,3 & 1,3 & 1,3 & 1,3 \\
\hline
\end{tabular}

Figura 20 - Evolução da relação entre a porcentagem de discentes da educação superior e a porcentagem da população de cada região do Brasil no período 1995-2003

Fonte: Elaborado pelo autor a partir de BRASIL/Seppir, 2006a e INEP, 2004; 2005a; 2006a. *obs: Exclusive a população rural de Rondônia, Roraima, Amapá, Amazonas, Pará e Acre. 
A cobertura no atendimento da educação superior em termos da proporção da população das diferentes regiões do país também é um indicador da eqüidade de um SES. Assim, a eqüidade também deve ser medida em termos de equilíbrio em relação à população no atendimento às diferentes regiões do país. Nesse sentido, a Figura 20 demonstra um quadro de relativa estabilidade na evolução da relação entre a porcentagem de discentes da educação superior e a porcentagem da população de cada região do Brasil no período 1995-2003. No período, as regiões Norte e Sudeste aproximaram-se do equilíbrio entre as suas porcentagem de discentes e a porcentagem da população em relação a todo o país. Por outro lado, a região Centro-Oeste, no mesmo período, distanciou-se do ponto de equilíbrio, ou seja, aumentou a porcentagem de discentes em relação à porcentagem de população. As regiões Sul e Nordeste foram as que menos apresentaram alterações nesse aspecto, com o Sul distanciando-se e o Nordeste aproximando-se do ponto de equilíbrio. Dessa forma, pode-se constatar uma tendência de estabilidade na cobertura no atendimento da educação superior em termos da proporção da população das diferentes regiões do país.

N4- Porcentagem de cursos com conceitos A ou B no Provão por região do Brasil

\begin{tabular}{|l|r|r|r|r|r|r|}
\hline Ano & $\mathbf{1 9 9 8}$ & $\mathbf{1 9 9 9}$ & $\mathbf{2 0 0 0}$ & $\mathbf{2 0 0 1}$ & $\mathbf{2 0 0 2}$ & $\mathbf{2 0 0 3}$ \\
\hline Norte & $11 \%$ & $13 \%$ & $11 \%$ & $8 \%$ & $13 \%$ & $10 \%$ \\
\hline Nordeste & $22 \%$ & $27 \%$ & $26 \%$ & $25 \%$ & $23 \%$ & $25 \%$ \\
\hline Centro-Oeste & $26 \%$ & $26 \%$ & $35 \%$ & $36 \%$ & $31 \%$ & $29 \%$ \\
\hline Sudeste & $29 \%$ & $30 \%$ & $32 \%$ & $30 \%$ & $29 \%$ & $29 \%$ \\
\hline Sul & $39 \%$ & $41 \%$ & $41 \%$ & $36 \%$ & $36 \%$ & $36 \%$ \\
\hline
\end{tabular}

Figura 21 - Evolução da porcentagem de cursos com conceitos A ou B no Provão por regiões do Brasil no período 1998-2003

Fonte: Elaborado pelo autor a partir de INEP, 2003 e INEP, 2006b.

O equilíbrio no desempenho e aproveitamento dos cursos nos exames de aprendizagem nas diferentes regiões de um país também é um importante indicador do nível de eqüidade de um SES. A Figura 21 demonstra, por amostragem, a estabilidade na análise da evolução da porcentagem de cursos que obtiveram conceitos A ou B no Provão nas diferentes regiões do Brasil no período 19982003. A região Norte do país manteve no período uma taxa de aproximadamente 10\% de cursos com conceitos A ou B no Provão; as regiões Nordeste, CentroOeste e Sudeste mantiveram no período posições intermediárias na medição 
do desempenho dos cursos com conceitos A ou B, e a região Sul manteve-se à frente nesse quesito, com taxas superiores a 35\%. Em síntese, pode-se dizer que o nível de iniqüidade entre as regiões do país em relação ao desempenho no Provão manteve-se praticamente inalterado no período 1998-2003.

\section{Análise da qualidade do SESB: relevância, eqüidade, diversidade e eficácia}

O objetivo da avaliação desenvolvidas neste trabalho não é emitir juízo de valor definitivo sobre a qualidade do Sesb no período estudado, tampouco comparar o Sesb com o desempenho de SES de outros países ${ }^{3}$. A idéia central está relacionada ao acompanhamento do desenvolvimento e comportamento dos indicadores do Sesb no período 1994-2003, quando as políticas de mercantilização ocorreram de forma mais visível no Brasil, e, dessa forma, verificar se ocorreram ou não desenvolvimento e evolução na qualidade no contexto específico do próprio sistema.

As medições realizadas sobre os indicadores que possuem informações e dados disponíveis apontam para um quadro geral do Sesb de estabilidade, visto que nos três grupos do sistema de indicadores (entradas, processo e resultados) a maior parte dos aspectos considerados apresentou regressão ou estabilidade. Dos dezenove indicadores medidos para o Sesb dentro do período 1994-2003, pode-se dizer que seis (A1, A2, A3, B1, G1 e I1) apresentaram regressões, cinco (D1a, D1b, J1, L1 e M2) apresentaram avanços e dez (D2, H2, K1, L5, M3, N1, N3 e N4), a maioria absoluta, não apresentaram alterações relevantes (Figura 22). Além disso, a maior parte dos indicadores de resultados do Sesb apresentou tendência de estabilidade dentro do período estudado, entre 1994 e 2003. Se, por um lado, a medição de tais indicadores permitiu encontrar avanços claros em alguns aspectos, como na taxa de escolarização líquida da educação superior, na quantidade de discentes por docente com título de doutor ou mestre, na porcentagem da PEA com diploma superior e na quantidade de cursos de graduação que se submeteram aos procedimentos de avaliação, noutro sentido também permitiu encontrar preocupantes regressões no financiamento do governo federal nas Ifes, como no percentual do PIB, nos dispêndios com P\&D na educação superior, no percentual de docentes com dedicação integral e na redução da quantidade de discentes stricto sensu para cada bolsista no exterior.

3 A referência utilizada para analisar o desenvolvimento da qualidade do Sesb são os próprios indicadores do Sesb num período de dez anos (1993-2004). Assim, não foi considerado um parâmetro, um padrão ou uma régua a priori, um padrão meta-internacional ou outro. 


\begin{tabular}{|c|c|c|}
\hline Sistema & Indicador & Evolução \\
\hline \multirow{7}{*}{ Entradas } & $\begin{array}{l}\text { A1 - Investimentos do Governo Federal nas IFES como percentual } \\
\text { do PIB }\end{array}$ & Regrediu \\
\hline & A2 - Participação do Governo Federal nos investimentos do SFE & Regrediu \\
\hline & A3 - Investimentos do Governo Federal nas IFES por discentes & Regrediu \\
\hline & $\begin{array}{l}\text { B1 - Investimentos do Governo Federal em P\&D na educação } \\
\text { superior }\end{array}$ & Regrediu \\
\hline & $\begin{array}{l}\text { D1a- Quantidade de discentes por cada docente com título de } \\
\text { doutor no Sesb }\end{array}$ & Avançou \\
\hline & $\begin{array}{l}\text { D1b- Quantidade de discentes por cada docente com título de } \\
\text { mestre ou doutor no Sesb }\end{array}$ & Avançou \\
\hline & D2- Quantidade de discentes por cada docente no Sesb & Estável \\
\hline \multirow{4}{*}{ Processo } & $\begin{array}{l}\text { G1- Porcentagem de docentes com dedicação integral e parcial } \\
\text { no Sesb }\end{array}$ & Regrediu \\
\hline & $\begin{array}{l}\text { H2- Porcentagem dos discentes por grandes áreas do conheci- } \\
\text { mento no Sesb }\end{array}$ & Estável \\
\hline & $\begin{array}{l}\text { I1- Quantidade de discentes de mestrado e doutorado para cada } \\
\text { bolsista no exterior }\end{array}$ & Regrediu \\
\hline & $\begin{array}{l}\text { J1- Quantidade de cursos de graduação avaliados pelo ENC } \\
\text { (Provão) }\end{array}$ & Avançou \\
\hline \multirow{8}{*}{ Resultados } & $\begin{array}{l}\text { K1- Porcentagem de cursos das IFES e da rede privada com con- } \\
\text { ceitos A ou B no Provão }\end{array}$ & Estável \\
\hline & L1- Taxa de escolarização líquida da educação superior brasileira & Avançou \\
\hline & $\begin{array}{l}\text { L5- Porcentagem de concluintes em relação a ingressantes } 4 \text { anos } \\
\text { antes no Sesb }\end{array}$ & Estável \\
\hline & $\begin{array}{l}\text { M2- Porcentagem da população com diploma superior da PEA } \\
\text { no Brasil }\end{array}$ & Avançou \\
\hline & $\begin{array}{l}\text { M3- Quantidade de pessoas inseridas em ocupação técnico- } \\
\text { científica por publicação }\end{array}$ & Estável \\
\hline & $\begin{array}{l}\text { N1- Comparação entre as taxas de escolarização líquida das po- } \\
\text { pulações negra e branca na educação superior }\end{array}$ & Estável \\
\hline & $\begin{array}{l}\text { N3- Evolução da relação entre porcentagem de discentes e de } \\
\text { população das regiões do Brasil }\end{array}$ & Estável \\
\hline & $\begin{array}{l}\text { N4- Porcentagem de cursos com conceitos A ou B no Provão por } \\
\text { região do Brasil }\end{array}$ & Estável \\
\hline
\end{tabular}

Figura 22 - Evolução dos indicadores do Sesb no período 1994-2003.

Fonte: Elaborado pelo autor. 
Alguns indicadores de entradas refletem claramente a opção política de priorizar a rede privada como estratégia de ampliação do sistema: o investimento estatal foi ultrapassado pelo investimento privado no âmbito do SFE, o investimento do governo federal nas Ifes regrediu quando analisado como percentual do PIB e os dispêndios do governo federal em P\&D com o MEC diminuíram entre 1996 e 2002.

No âmbito dos indicadores de processo e resultados, pode-se dizer que o crescimento da rede privada refletiu de forma positiva principalmente ao impor a implantação de procedimentos de avaliação externa dos cursos de graduação, ao propiciar a ampliação das taxas de atendimento da educação superior (taxas de escolarização líquida e bruta) e ao ampliar o percentual de pessoas com diploma superior no conjunto da PEA brasileira. Entretanto, os avanços decorrentes da política de expansão do Sesb por meio do crescimento da rede privada parecem ter se limitado a esses aspectos, visto que todos os demais indicadores medidos em nível de processo e resultados permaneceram estáveis ou regrediram. Além da constatação de evidente redução no percentual de docentes com dedicação integral à educação superior, também se constatou diminuição no nível de internacionalização do sistema, visto que diminuiu a quantidade de discentes stricto sensu para cada bolsista no exterior.

Quando se consideram o financiamento estatal federal e o privado, é possível verificar um significativo aumento do financiamento total do Sesb, que aumentou quase R\$ 5 milhões em seis anos no SFE (entre 1996 e 2001). Entretanto, tal aumento global de financiamento não resultou em evidentes melhorias em aspectos de processo (dedicação docente e internacionalização) e resultados (aprendizagem e desempenho discente nas diferentes regiões, eqüidade no atendimento nas diferentes regiões e conclusão dos cursos no prazo adequado) do Sesb. Da mesma forma, as medições de indicadores vinculados às propriedades de eqüidade (atendimento entre as diferentes raças), diversidade (quantidade de matrículas nas diferentes áreas do conhecimento), relevância (produtividade nas publicações internacionais) e eficácia (aprendizagem e desempenho discente nas diferentes redes) indicaram que a ampliação do financiamento global do Sesb não reverteu em melhorias na qualidade.

Indiscutivelmente a educação superior brasileira está se expandindo e tal fenômeno tem ocorrido sobretudo pelo crescimento da rede privada em termos de quantidade de IES, cursos e matrículas. Dessa forma, a limitação no desenvolvimento da qualidade do Sesb parece ser conseqüência da expansão no financiamento e no número de IES e matrículas basearem-se na rede privada, pois nela estão alguns dos piores desempenhos de importantes indicadores de 
qualidade na educação superior. Nas IES privadas encontram-se, por exemplo, a pior relação discente por docente com título de doutor, os menores números de projetos de pesquisas e produção científica, a menor porcentagem de cursos com conceitos A ou B no Provão e as mais baixas porcentagem de docentes com dedicação integral à educação superior.

A divulgação do Enade do ano de 2005 reforça tal análise ao apontar para a queda de qualidade onde ocorreu uma maior expansão privada. Enquanto uma das regiões menos desenvolvidas do país (Nordeste) alcançou um percentual de $29 \%$ de cursos com os conceitos mais altos do Enade, a região mais desenvolvida (Sudeste), local onde surgiu a maior quantidade de cursos privados nos últimos anos, alcançou $27 \%$ de cursos com os conceitos mais altos (NORDESTE ..., 2006). Assim, como a maior parte das novas matrículas no Sesb ocorreu na rede privada, pode-se afirmar que no período 1994-2003, gradativa e progressivamente, uma porcentagem maior de discentes teve acesso à rede de mais baixa qualidade.

Evidentemente, não se pode negar que ocorreram alguns avanços em termos quantitativos no Sesb nos últimos tempos, porém também houve regressões e as medições realizadas nos indicadores com dados disponíveis para o período 1994-2003 indicaram um quadro geral de estabilidade nos diferentes aspectos de qualidade do Sesb. Assim, a falta de evidências claras de melhorias, em termos de eqüidade, diversidade, relevância e eficácia, indicam que, no período estudado, a qualidade do Sesb não avançou de forma significativa, ou seja, a medição e análise global do conjunto de indicadores sobre a educação superior brasileira apontam que a qualidade do sistema não evoluiu em tempos de mercantilização.

\section{Conclusão}

Nos últimos anos, diversos países têm vivenciado ampla expansão da lógica e dos princípios do mercado no âmbito de seus sistemas de educação superior. Os impactos e conseqüências de tal emergência da mercantilização na educação superior ainda não são completamente conhecidos. Portanto, questões relacionadas às conseqüências da mercantilização e dos mercados na educação superior ainda carecem de estudos e investigações que apontem para respostas elucidativas acerca do assunto (TEIXEIRA et al, 2004). Com vistas a contribuir na construção de respostas confiáveis sobre os impactos da mercantilização no desenvolvimento da qualidade dos sistemas de educação 
superior, o presente trabalho desenvolveu a avaliação da qualidade do Sesb durante o período 1994-2003.

A medição de indicadores demonstra que a educação superior brasileira expandiu-se significativamente no período 1994-2003, mais notadamente a partir do ano de 1997, baseando-se, fundamentalmente, na ampliação da rede privada com fins lucrativos (for profit) e em instituições não-universitárias. O número de universidades estatais e de universidades sem fins lucrativos (registered charities) praticamente permaneceu o mesmo e o porcentual de matrículas das Ifes diminuiu consideravelmente em relação ao conjunto do Sesb.

Num conjunto de dezenove indicadores medido, apenas cinco apresentaram melhora quantitativa significativa. Nos três grupos do sistema de indicadores (entradas, processo e resultados) a maior parte dos aspectos medidos apresentou regressão ou estabilidade, ou seja, a maioria dos indicadores apresentou tendência clara de estabilidade no período 1994-2003, inclusive aqueles relativos especificamente às propriedades de eqüidade, diversidade, eficácia e relevância.

Evidentemente, a opção política de expandir o sistema por meio de IES privadas, com fins lucrativos e de organização acadêmica não universitária tem relação com a constatação de que a maior parte dos indicadores medidos não avançou no período 1994-2003. A rede privada possui alguns dos piores desempenhos no Sesb, como, por exemplo, o mais baixo percentual de cursos com conceitos A ou B no Provão, as piores relações entre discentes e docentes com título de doutor e uma reduzida participação nas publicações científicas relevantes. Em razão da própria natureza dos mercados e das IES privadas com fins lucrativos, que requerem lucros, tais instituições necessitam cobrar mensalidades superiores aos seus custos e respondem prioritariamente às demandas dos indivíduos e organizações que as financiam, não às da sociedade como um todo. As ciências básicas e as humanidades, por exemplo, são essenciais para o desenvolvimento das sociedades, mas seguramente receberão recursos insuficientes se norteadas apenas pela lógica do mercado. Além disso, o crescimento do número de IES privadas com fins lucrativos tem pressionado instituições sem fins lucrativos a reduzirem investimentos em projetos de relevância social com vistas a manterem a sustentabilidade econômico-financeira. Portanto os maiores problemas em expandir o sistema por meio de IES privadas, principalmente as com fins lucrativos, estão ligados a evidentes limitações no desenvolvimento da eqüidade, relevância social e qualidade do SES.

De forma sucinta, pode-se dizer que nos últimos tempos o Brasil optou, por um lado, em expandir a rede que possuía alguns dos piores indicadores de qualidade e, por outro, em reduzir o investimento estatal que se destinava à rede 
mais qualificada com vistas a, principalmente, ampliar as taxas de atendimento. Os indicadores de atendimento, de fato, melhoraram no período estudado. A taxa de escolarização bruta cresceu de 8,1\%, em 1991, para 17,3\%, em 2004, porém, ainda assim, o Brasil continuou com taxas bem inferiores às de países como Argentina (48\% em 1999), Portugal (50\% em 2002), Coréia (78\% em 2002) e EUA (73\% em 2002). Além disso, a possibilidade de ampliação do atendimento por meio da rede privada parece estar se esgotando. No ano de 2002 mais de 550 mil vagas não foram preenchidas nos processos seletivos do setor privado em razão da incapacidade dos alunos de fazerem frente às mensalidades, ou seja, antes mesmo de atingir plenamente um de seus principais objetivos, a política de expansão privada já se demonstrou insuficiente.

Mas qual o "custo" dessa ampliação via rede privada e da própria mercantilização da ES para os níveis de eqüidade e de relevância social do sistema? Quais as conseqüências qualitativas para o Sesb dessa política de educação superior? Se, por um lado, no período 1994-2003, o Sesb parece ter alcançado alguma produtividade em aspectos como o aumento da titulação dos docentes e na ampliação das taxas de atendimento, por outro, demonstra que tais avanços não resultaram em relevância significativa, pois a taxa de escolarização líquida de $10 \%$ e a produção científica relevante são ainda insuficientes para um país em fase de desenvolvimento como o Brasil. Assim, pode-se dizer que a expansão privada e a emergência de mercados não estão trazendo todos os resultados positivos para o Sesb preditos pelos organismos multilaterais financeiros. A mercantilização da educação superior brasileira não respondeu satisfatoriamente às necessidades quantitativas mais imediatas, como o aumento das taxas de atendimento, nem às qualitativas, como as propriedades de relevância, eqüidade, eficácia e diversidade do Sesb.

A pergunta que surge, então, é como ampliar o atendimento na educação superior brasileira com qualidade? Teria o Estado condições de financiar uma expansão adequada aos padrões internacionais com qualidade? Ou o Brasil deveria optar por uma estratégia hibrida de financiamento estatal e privado, com ampla diversificação (ex: cursos noturnos e rede tecnológica) e forte regulação e controle de qualidade? Tais questões precisam ser respondidas com urgência.

O maior risco da ampliação da perspectiva mercantilista e da visão da educação como serviço comercial parece ser o de se impossibilitar o próprio desenvolvimento social e o crescimento econômico de países como o Brasil, visto que o estabelecimento de parte da educação superior como bem público é fundamental para sustentar um projeto de nação. Como este trabalho indicou que as tendências de mercantilização não deram respostas plenamente satisfa- 
tórias para expandir o SES com qualidade, faz-se necessário que a academia, o governo e a própria sociedade reflitam e busquem novas formas e políticas públicas para que o Sesb possa cumprir a função primeira da educação superior e contribuir com o desenvolvimento sociocultural e o crescimento econômico do país.

\section{REFERÊNCIAS}

BERTOLIN, Julio C. G. Avaliação da qualidade do sistema de educação superior brasileiro em tempos de mercantilização - período 1994-2003. 2007. Tese (Doutorado em Educação) - Universidade Federal do Rio Grande do Sul, Porto Alegre, 2007a.

BERTOLIN, Julio C. G. Indicadores em nível de sistema para avaliar o desenvolvimento e a qualidade da educação superior brasileira. Avaliação, Campinas; Sorocaba, v. 12, n. 2, p. 309-331, jun. 2007b.

BRASIL. Boletim de dados físicos e orçamentários $\mathbf{n}^{\circ}$ 8; instituições federais de ensino supervisionadas pelo MEC : 1994-2001. Brasília: MEC/ SESu, 2002.

BRASIL. Ministério da Ciência e Tecnologia - Brasil. Indicadores de Ciência \& Tecnologia 2002. Brasília: MCT, 2004.

BRASIL. Secretaria Especial de Políticas de Promoção da Igualdade Racial. Presidência da República do Brasil. Disponível em <http:// www.planalto.gov.br/seppir/pesquisas_indicadores/genero/retrato_ das_desiguladades/tabelas/2_Educacao/2.7.pdf\#search=\%22taxa\%20 escolariza $\% \mathrm{C} 3 \% \mathrm{~A} 7 \% \mathrm{C} 3 \% \mathrm{~A} 30 \% 22>$. Acesso em: 25 set. $2006 \mathrm{a}$.

BANCO CENTRAL DO BRASIL. Séries temporais. Disponível em: <http:// www.bancocentral.gov.br/?SERIETEMP $>$. Acesso em: 11 set. $2006 \mathrm{~b}$.

COORDENAÇÃO DE APERFEIÇOAMENTO DE PESSOAL DE NÍVEL SUPERIOR - CAPES. Relatório de Gestão. 2003. Brasília: CAPES, 2004.

CONSELHO NACIONAL DE DESENVOLVIMENTO CIENTÍFICO E TECNOLÓGICO - CNPq. Estatísticas e Indicadores do Fomento. Disponível em: $<$ http://www.cnpq.br/estatisticas/bolsas/totais.htm $>$. Acesso em: 23 set. 2006. 
DIAS SOBRNHO, José; RISTOFF, Dilvo I. (Org.). Avaliação e compromisso público: a educação em debate. Florianópolis: Insular, 2003. GARCÍA, Mercedes G. Evaluación y calidad de los sistemas educativos. In: RAMÍREZ, Teresa G. (Org.). Evaluación y gestión de la calidad educativa. Málaga: Ediciones Aljibe, 2000.

INSTITUTO NACIONAL DE ESTUDOS E PESQUISAS EDUCACIONAIS ANÍSIO TEIXEIRA - INEP. Relatório do Exame Nacional de Cursos 2003 - relatório síntese. Brasília: INEP, 2003.

. Mapa da Educação Superior do Brasil. Brasília: INEP, 2004.

. Censo da educação superior 2004 - resumo técnico. Brasília: INEP, 2005a.

. Dados estatísticos da educação superior - censo 1991-2003. Brasília: INEP, 2005b. 6 arquivos digitais (Excel).

. Censo da Educação Superior 2003 - Resumo Técnico. Disponível em: < http://www.inep.gov.br/download/superior/censo/2004/resumo_ tecnico_050105.pdf >. Acesso em: 28 jul. 2006a.

. Relatórios Sínteses dos Exames Nacional de Cursos. Disponível em: < http://www.inep.gov.br/superior/provao/sintese/sintese.htm $>$. Acesso em: 24 set. 2006b.

INTERNET PRODUTO INTERNO BRUTO - IPIB. Valores do PIB Brasileiro. Disponível em: <http://www.ipib.com.br/>. Acesso em: 10 set. 2006.

JOHNSTONE, D. Bruce. The financing and management of higher education: a status report on worldwide reforms. Washington, DC: The World Bank, 1998.

LEITE, Denise. Institutional evaluation, management practices and capitalist redesign of universities. In: AMARAL, A; LYNN MEEK, V.; LARSEN, I.. (Org.). The higher education managerial revolution? Netherlands, Dordretcht: Kluwer academic Publishers, 2003.

MCCOWAN, T. O crescimento da educação superior privada no Brasil: implicações para as questões de equidade, qualidade e benefício público. Arquivos analíticos de políticas educativas, Rio de Janeiro, v. 13, n. 27, abr. 2005. 
NAVARRA. Sistema de indicadores de la educación de Navarra 2003.

Navarra: Gobierno de Navarra, 2004.

NORDESTE TEM NOTAS MELHORES QUE O SUDESTE. Folha de S. Paulo, São Paulo, 10 ago. 2006. Seção Folha Cotidiano.

SANTOS, Boaventura de Souza. A universidade no século XXI: para um reforma democrática e emancipatória da universidade. São Paulo: Cortez, 2004.

SCHWARTZMAN, Jacques. O financiamento do ensino superior no Brasil na década de 90. In: SOARES, Maria Suzana A. (Org.). A educação superior no Brasil. Brasília: Coordenação de Pessoal de Nível Superior, 2002.

SGUISSARDI, Valdemar. Universidade pública estatal: entre o público e o privado/mercantil. Educação \& Sociedade, Campinas, v. 26, n. 90, p. 191222, jan./abr. 2005.

TEIXEIRA, Pedro et al. Markets in higher education: rhetoric or reality? Netherlands: Kluwer Academic Publishers, 2004.

UNITED NATIONS EDUCATIONAL, SCIENTIFIC AND CULTURAL ORGANIZATION (UNESCO). Marco conceptual. Documentos Laboratorio Latinoamericano de Evaluación de la calidad de la educación. Santiago, Chile: Lecce, Orealc/Unesco, 1997. 